\title{
Electromigration Activation Energies in Alternative Metal Interconnects
}

\author{
Sofie Beyne ${ }^{\circledR}$, Olalla Varela Pedreira, Herman Oprins ${ }^{\circledR}$, Ingrid De Wolf, Zsolt Tőkei, and Kristof Croes
}

\begin{abstract}
The electromigration (EM) activation energy $\left(E_{A}\right)$ of alternative metals, such as $R u$ and Co, was obtained using low-frequency noise (LFN) measurements. High activation energies were expected, but values of $\approx 1 \mathrm{eV}$ are found, most likely related to diffusion along with the metaldielectric interface. Wafer-level accelerated EM tests were carried out to compare the LFN $E_{A}$ to the EM $E_{A}$ in the $\mathrm{Ru}$ wires. The calculation of the $E M E_{A}$ is found to be strongly dependent on the assumed temperature profile in the wire due to Joule heating $(\mathrm{JH})$. The temperature profile was calculated analytically, assuming the contacts are at ambient temperature. For a void forming in direct proximity of the contact, the EM $E_{A}$ then matches the LFN $E_{A}$. For a void at average wire temperature (ambient $+\mathrm{JH}$ ), $\mathrm{E}_{\mathrm{A}} \approx 2 \mathrm{eV}$. In addition to demonstrating the application of LFN to study EM in alternative metals, this article also cautions for the impact of $\mathrm{JH}$ on the calculation of $E_{A}$ in interconnects.
\end{abstract}

Index Terms-Activation energy, alternative metals, cobalt, electromigration (EM), interconnects, low-frequency noise (LFN), reliability.

\section{INTRODUCTION}

$\mathbf{T}$ HE continuous downscaling of electronic components leads to challenges for the development of both front end and back end of lines (FEOL and BEOL, respectively). In recent years, $\mathrm{RC}$ delays caused by $\mathrm{BEOL}$ interconnects are overtaking FEOL delays. This is a result of the increased resistivity of $\mathrm{Cu}$ at narrow dimensions [1]. Moreover, also the electromigration (EM) performance of $\mathrm{Cu}$ interconnects below 30-nm linewidth is severely degraded [2]-[4]. Therefore, alternative metals, such as cobalt [5]-[7] and ruthenium [7]-[9], are being investigated as replacements for $\mathrm{Cu}$. The resistivity of $\mathrm{Co}$ and $\mathrm{Ru}$ versus $\mathrm{Cu}$ has already been studied extensively [10], [11], but studies of their EM performance remain limited [7], [12]-[14]. It was generally expected that $\mathrm{Ru}$ and Co would have very high EM activation energies because of their high melting temperature [15]. Nevertheless, it was found that tungsten, which has an even higher melting

Manuscript received July 25, 2019; revised October 15, 2019; accepted October 19, 2019. This work was supported by the Fund for Scientific Research in Flanders, FWO, under Grant SB1S21616N. The review of this article was arranged by Editor M. S. Bakir. (Corresponding author: Sofie Beyne.)

S. Beyne and I. De Wolf are with the Department of Materials Science and Engineering, Katholieke Universiteit Leuven, Leuven, 3001 Leuven, Belgium, and also with IMEC, 3001 Leuven, Belgium (e-mail: sofie.beyne@imec.be).

O. V. Pedreira, H. Oprins, Z. Tökei, and K. Croes are with IMEC, 3001 Leuven, Belgium.

Color versions of one or more of the figures in this article are available online at http://ieeexplore.ieee.org.

Digital Object Identifier 10.1109/TED.2019.2949196 temperature than $\mathrm{Ru}$ and $\mathrm{Co}$, had an EM activation energy of $0.69 \mathrm{eV}$ [16], in spite of long lifetimes being observed. Initial reports of the EM activation energy of $\mathrm{Co}$ and $\mathrm{Ru}$ showed values $\approx 2 \mathrm{eV}$ [5], [7]. However, concerns may arise regarding the adequacy of these numbers, as they were obtained under highly accelerated EM test conditions. Furthermore, it is not clear to what extent Joule heating (JH) may have affected the calculation of these activation energies.

$\mathrm{EM}$ experiments on $\mathrm{Co}$ and $\mathrm{Ru}$ are challenging because they require very high temperature and current density in order to observe failures within a reasonable amount of time [12]. At such elevated stress conditions, the failure mechanisms may be different than under normal operation and might even result in a change in microstructure [5], [13]. To address this problem, we have proposed $1 / f$ or, more generally, lowfrequency noise (LFN) measurements to characterize EM activation energies [16]-[18]. LFN measurements allow studying the EM mechanisms much closer to operating conditions and in significantly shorter periods of time (a matter of days instead of weeks).

In this article, we report the activation energies found by applying LFN measurements to $\mathrm{Co}$ and $\mathrm{Ru}$ interconnects. The activation energy of $\mathrm{Ru}$ is compared with the result obtained using wafer-level EM tests. We show that understanding the temperature in the interconnect due to $\mathrm{JH}$ is crucial for a correct extraction of the EM activation energy.

This article extends the 2019 International Interconnect Technology Conference article in [19].

\section{EXPERIMENTAL}

\section{A. Sample Description}

We studied five types of Ru interconnects, four of which are fabricated using the subtractive patterning technique described in [8] and one type using the spacer defined integration scheme described in [9] with an aspect ratio (AR) 1. We refer to these two types of lines as "metal etch" and "spacer-defined Ru," respectively. The $\mathrm{Ru}$ samples are labeled $\mathrm{Ru}$ _1- $\mathrm{Ru}$ _5. The $\mathrm{Ru}$ lines are $7 \mu \mathrm{m}$ long and the dielectric is $\mathrm{SiO}_{2}$, and other details are listed in Table I. The cobalt lines studied in this article are fabricated using a damascene vehicle [20] with a low- $k$ dielectric and are 22-nm-wide with an AR 2 and $100 \mu \mathrm{m}$ long. Fig. 1 shows the grain structure of the $R u$ lines (a) $R u \_1$, (b) $\mathrm{Ru} \_3$, and (c) $\mathrm{Ru}$ _5. Ru_1 was the first iteration of the process and had significantly smaller grain size than the other samples. The roughness of the samples $\mathrm{Ru} \_1-\mathrm{Ru} 44$ is large because of the metal etch used in the process [8]. In Fig. 1(c), one can 
TABLE I

SAMPLE DetAILs. FGA AT $420^{\circ} \mathrm{C}$ FOR $20 \mathrm{~min}$

\begin{tabular}{|c|c|c|c|c|c|c|}
\hline & $\mathrm{Ru} \_1$ & $\mathrm{Ru}_{-} 2$ & $\mathrm{Ru} \_3$ & $\mathrm{Ru} \mathrm{L}_{-}$ & $\mathrm{Ru} \_5$ & Co \\
\hline Process & Metal Etch & Metal Etch & Metal Etch & Metal Etch & Spacer-defined & Damascene \\
\hline Deposited Thickness & $10 \mathrm{~nm}$ & $10 \mathrm{~nm}$ & $10 \mathrm{~nm}$ & $8 \mathrm{~nm}$ & $18 \mathrm{~nm}$ & $22 \mathrm{~nm}$ \\
\hline Adhesion layer & $0.3 \mathrm{~nm}$ TiN & $0.3 \mathrm{~nm}$ TiN & NA & $0.3 \mathrm{~nm}$ TiN & $0.3 \mathrm{nmTiO}_{2}$ & $0.3 \mathrm{nmTiO}_{2}$ \\
\hline FGA & $\sqrt{\top}$ & $x$ & $\sqrt{ }$ & $x$ & $\checkmark$ & $x$ \\
\hline Cross section $\sim \mathrm{nm}^{2}$ & 60 & 60 & 60 & 35 & 325 & 1000 \\
\hline
\end{tabular}
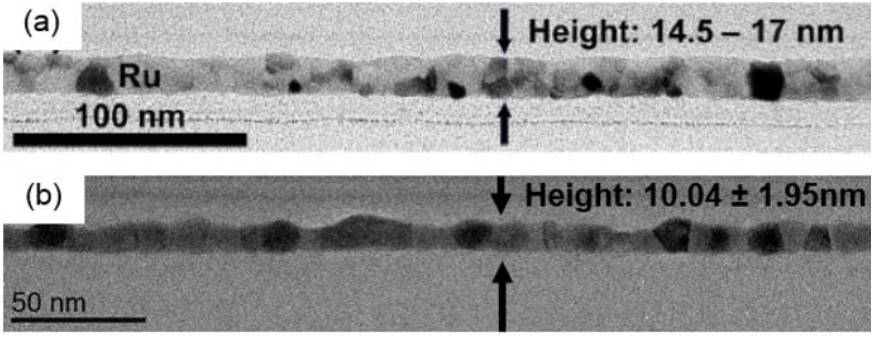

(c)

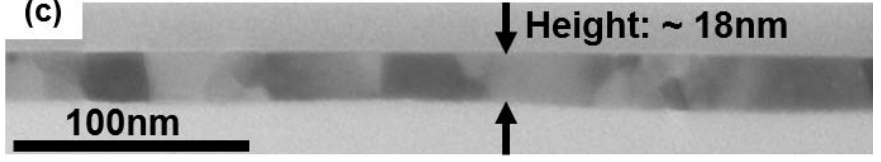

Fig. 1. Grain structure of the $R u$ lines $R u \_1, R u \_3$, and $R u \_5$. (a) is from the first iteration of the process and had smaller grain sizes than the others. The roughness of (a) Ru_1 and (b) $R u \_3$ is large because of the metal etch used in the process [8]. (c) Ru_5 lines are wider and have a much smoother surface because no metal etch was used [9]. In all cases, large grains that span the full thickness of the line can be observed.

see that $\mathrm{Ru} \_5$ has a much smoother surface as a result of the spacer defined integration scheme that was used for these samples [9].

\section{B. Low-Frequency Noise Measurements}

LFN measurements can be used to calculate activation energies of defect systems in nano-interconnects and the values obtained using LFN were found to correspond to the EM activation energy. For a detailed description regarding the LFN methodology, the reader is referred to previous publications [16]-[18]. In summary, the activation energies can be calculated from the temperature dependence of the LFN power spectral density (PSD), using the model of Dutta et al. [21], [22]. A distribution of activation energies $D\left(\mathrm{E}_{\mathrm{A}}\right)$ is calculated based on the PSD as

$$
D\left(E_{A}\right)=\frac{\omega}{k_{B} T} \mathrm{PSD}
$$

and the activation energy is given by

$$
E_{A}=-k_{B} T \ln \left(\omega \tau_{0}\right)
$$

where $k_{B}$ is the Boltzmann constant, T the temperature, $\omega$ the radial frequency, and $\tau_{0}$ the inverse attempt frequency. For $\mathrm{Ru}$, $\tau_{0}$ is $8 \cdot 10^{-14} \mathrm{~s}$, and for Co, $1.08 \cdot 10^{-13} \mathrm{~s}$.

The activation energy is then calculated by identifying the maximum in the distribution function $D\left(E_{A}\right)$.

The current density applied during the noise measurements was between 1 and $10 \mathrm{MA} / \mathrm{cm}^{2}$ for samples $\mathrm{Ru}_{-} 1-\mathrm{Ru}_{-} 4$, between 1.5 and $5 \mathrm{MA} / \mathrm{cm}^{2}$ for $\mathrm{Ru}_{-} 5$ and between 2.5 and $5 \mathrm{MA} / \mathrm{cm}^{2}$ for the cobalt lines. These current densities do not lead to EM damage within the time of the tests, making the LFN measurements nondestructive.

\section{Electromigration Tests}

The EM tests were performed on the samples of type $\mathrm{Ru} \_3-\mathrm{Ru}$ _5, with ambient temperatures ranging from $250{ }^{\circ} \mathrm{C}$ to $330^{\circ} \mathrm{C}$ and current densities between 200 and $650 \mathrm{MA} / \mathrm{cm}^{2}$. These current densities result in significant $\mathrm{JH}$, as will be discussed in Section III. Failure was defined as a $10 \%$ increase in resistance. At each stress condition, a lognormal distribution of the failure times was obtained and the median time to failure (MTF or $t_{50}$ ) was used to extract the activation energy using Black's law [23]

$$
t_{50}=\frac{A}{J^{n}} \exp \left(\frac{E_{A}}{k_{B} T}\right)
$$

where $A$ is an empirical parameter, $J$ the current density, $E_{A}$ the activation energy, and $T$ the temperature. $n$ is the current exponent.

\section{Fusing Current Density and Joule Heating}

The fusing current density, $J_{\text {Fuse }}$, is obtained by continuously increasing the voltage and measuring the current until failure occurs. This methodology also allows obtaining the $\mathrm{JH}$, $\Delta T$, in the line from the resistance change

$$
\Delta T=\frac{R-R_{0}}{R_{0} \cdot \mathrm{TCR}}
$$

with $R$ the line resistance at each measurement point and $R_{0}$ at $0{ }^{\circ} \mathrm{C}$ and TCR the temperature coefficient of resistance. This measurement allows to estimate the average wire temperature during EM stress.

\section{Results And Discussion}

\section{A. Low-Frequency Noise Measurements}

The calculation of activation energy by LFN measurements is shown in Fig. 2 for a representative $\mathrm{Ru}_{-} 3, \mathrm{Ru} \_5$, and $\mathrm{Co}$ sample. The activation energy is identified by the maximum in $D\left(E_{A}\right)$, calculated using (1) with the PSD evaluated at $f=$ $3 \mathrm{~Hz}$ for $\mathrm{Ru} \_3, f=1 \mathrm{~Hz}$ for $\mathrm{Ru} \_5$, and $f=7 \mathrm{~Hz}$ for Co. The calculated activation energies are shown for all the samples in Fig. 3. Fig. 3 demonstrates that the $E_{A}$ of both the $\mathrm{Ru}$ and Co lines is close to $1 \mathrm{eV}$. The type of process (metal etch or damascene) does not impact the $\mathrm{Ru} \mathrm{E}_{\mathrm{A}}$ and neither do the differences in grain structure and surface roughness (see Fig. 1). $R u_{-} 3$, however, does have a slightly lower $\mathrm{E}_{\mathrm{A}}$ 


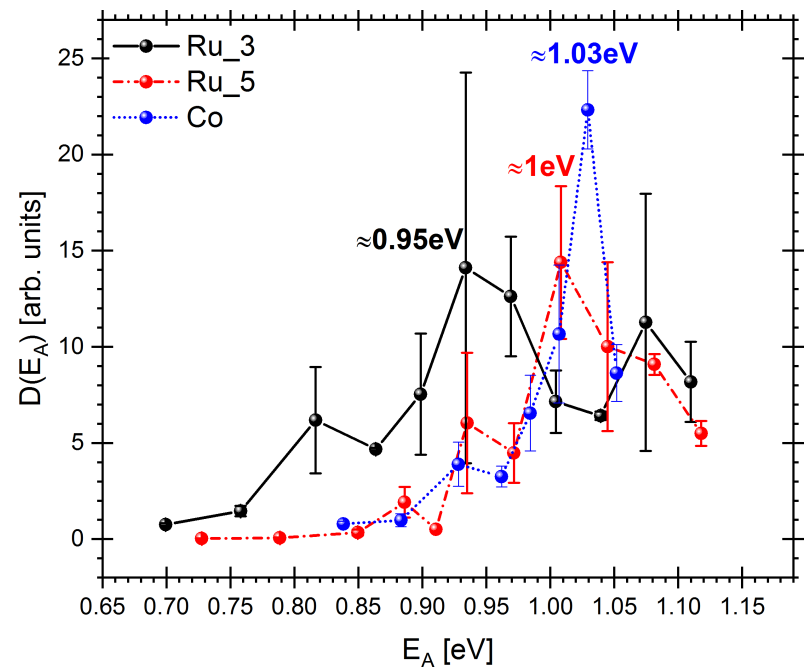

Fig. 2. Calculation of LFN activation energy for a Ru_3, Ru_5, and Co sample. The maximum in $D\left(E_{A}\right)$ indicates an activation energy of $0.95 \mathrm{eV}$ for Ru_3, 1 eV for Ru_5, and 1.03 eV for the cobalt lines.

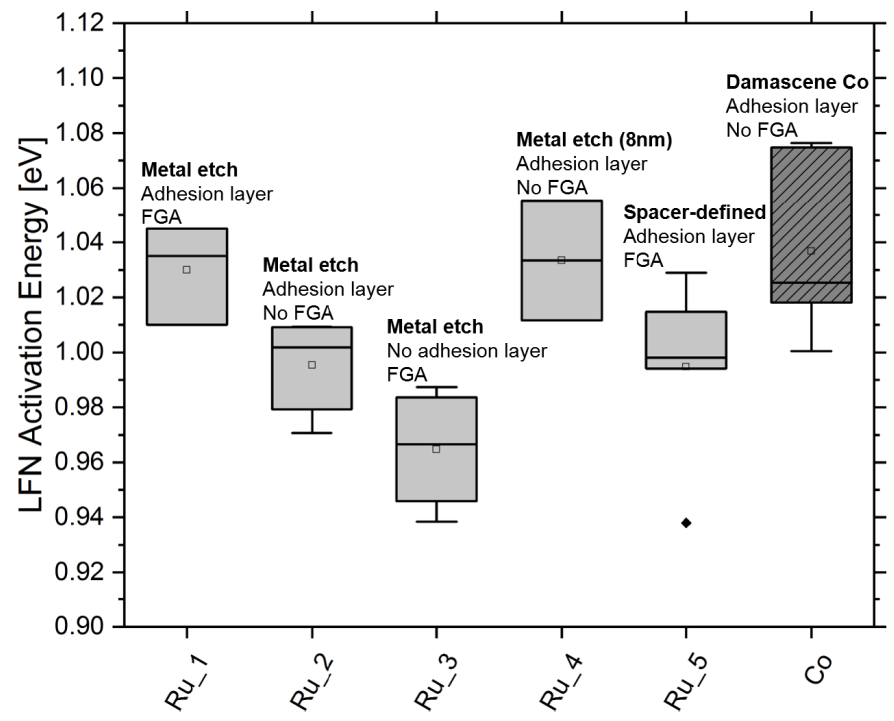

Fig. 3. Summary of the activation energies obtained with LFN for the $\mathrm{Ru}$ and Co lines. Only sample type Ru_3 has a lower activation energy.

$(-0.05 \mathrm{eV})$, which is attributed to its lack of adhesion layer, resulting in a weaker $\mathrm{SiO}_{2}-\mathrm{Ru}$ interface.

Note that our thermal chuck is limited to $200{ }^{\circ} \mathrm{C}$, and (2) shows that at $200{ }^{\circ} \mathrm{C}$ and $1 \mathrm{~Hz}, \mathrm{E}_{\mathrm{A}}$ is $1.15 \mathrm{eV}$, which means that we cannot determine activation energies above $1.1 \mathrm{eV}$. Larger values might be present, but would not be observable with our LFN measurements. Nevertheless, they may become dominant at the elevated test temperatures that were used in the EM experiments.

\section{B. Interpretation of the Activation Energy}

To determine the failure location, an accelerated waferlevel $\mathrm{EM}$ test was performed on samples $\mathrm{Ru} \_3$ and $\mathrm{Ru} \_5$ under the following test conditions: $J=300 \mathrm{MA} / \mathrm{cm}^{2}$ and $T=250{ }^{\circ} \mathrm{C}\left(+100{ }^{\circ} \mathrm{C} \mathrm{JH}\right)$ and $J=200 \mathrm{MA} / \mathrm{cm}^{2}$ and $T=330^{\circ} \mathrm{C}\left(+265^{\circ} \mathrm{C} \mathrm{JH}\right)$, respectively. Fig. 4 shows a darkfield (DF) scanning transmission electron microscopy (STEM)

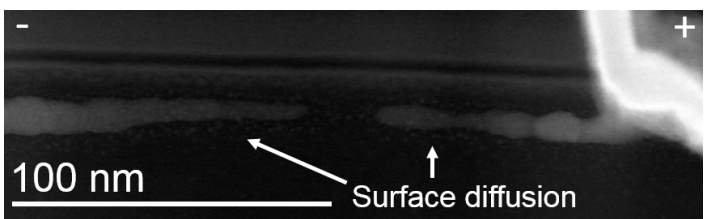

Fig. 4. DF STEM of an EM-induced void in a Ru_3 sample. Surface diffusion appears to be the dominant diffusion mechanism in this case. Note that voids form at the anode-end-of-line because holes are the majority charge carriers in Ru [12].

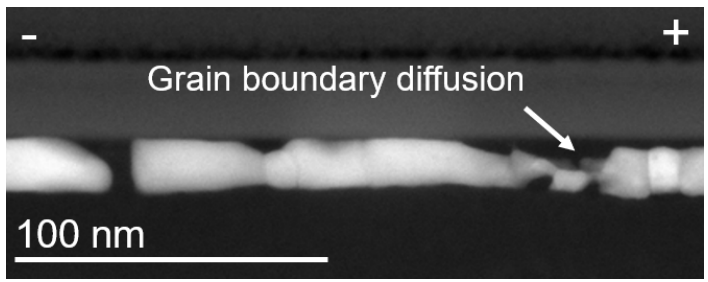

Fig. 5. DF STEM image of the failure location in a $R u$ _5 sample after EM. The arrow indicates that the void grew along the grain boundaries. $\mathrm{Ru}$ thinning is also visible at the top surface of certain grains.

image of the failure location in the Ru_3 sample. Here, surface diffusion appeared to be the dominant failure mechanism, which is not surprising considering the roughness of these lines [see Fig. 1(b)]. In addition, in the literature, activation energies around $1 \mathrm{eV}$ have been associated with surface diffusion in $\mathrm{Ru}$ [24], [25]. Note that the void was observed at the anode, indicating hole-wind EM (Ru is a p-type metal, which means that its majority charge carriers are holes) [12].

A DF STEM image of the failure location in a Ru_5 sample after EM is shown in Fig. 5. In this case, the void appears to progress by grain boundary diffusion, even though thinning of the surface is visible also here [compare with the smooth grain structure in Fig. 1(c)].

It should be noted that in both cases, the location of the flux divergence point (FDP) is different. In $R u_{-} 3$, the grains always span the full thickness of the line such that the FDP is at the contact only. In Ru_5, however, the line consists of both polycrystalline and bamboo grain segments. In that case, the voids would not always occur at the contact, rather they can form anywhere along the line, depending on the location of the local FDP.

Note that the location of the FDP does not influence the LFN measurements, but does change the EM-induced void location.

One should remark that even though a rather low $E_{A}$ is found in these $\mathrm{Ru}$ lines, their EM lifetime is still very long [12]. A similar observation was previously made for $W$, for which an $\mathrm{E}_{\mathrm{A}}$ of $0.69 \mathrm{eV}$ was found by both LFN and standard tests despite very long lifetimes being observed [16].

Using accelerated EM tests, Griggio et al. [5] reported activation energy of $1.89 \pm 0.19 \mathrm{eV}$ for Co in dual-damascene local interconnects on Intel's 10-nm logic. Hu et al. [7] found an $\mathrm{EM} \mathrm{E}_{\mathrm{A}}$ of $1.9 \mathrm{eV}$ in wider $\mathrm{Ru}$ lines with a barrier and values of $2.4-3.1 \mathrm{eV}$ for $\mathrm{Co}$, which they attributed to the bamboolike grain structure of their Co lines. Our LFN measurements indicate a much lower $\mathrm{E}_{\mathrm{A}}$ around $1 \mathrm{eV}$, which could be related to either grain boundary diffusion 
- Ru_4 = 0.3nm TiN + 8nm ALD Ru

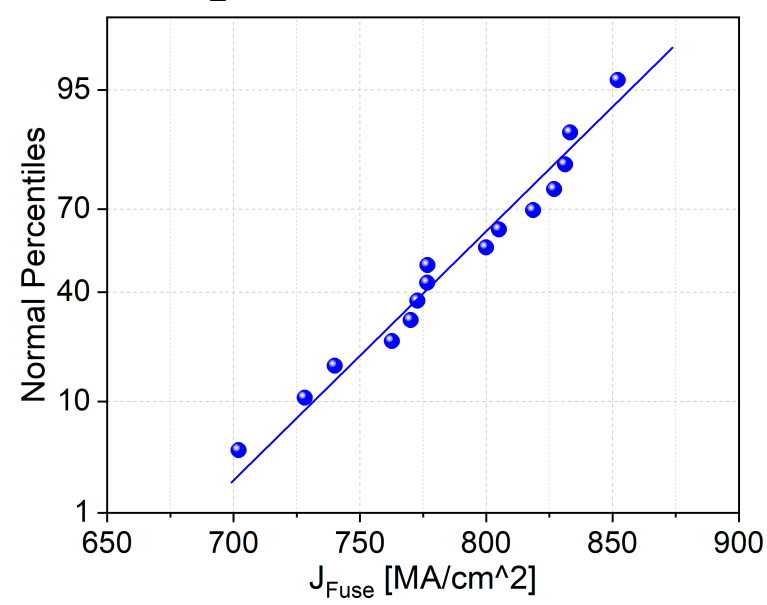

Fig. 6. Fusing current density $J_{\text {Fuse }}$ of Ru_4.

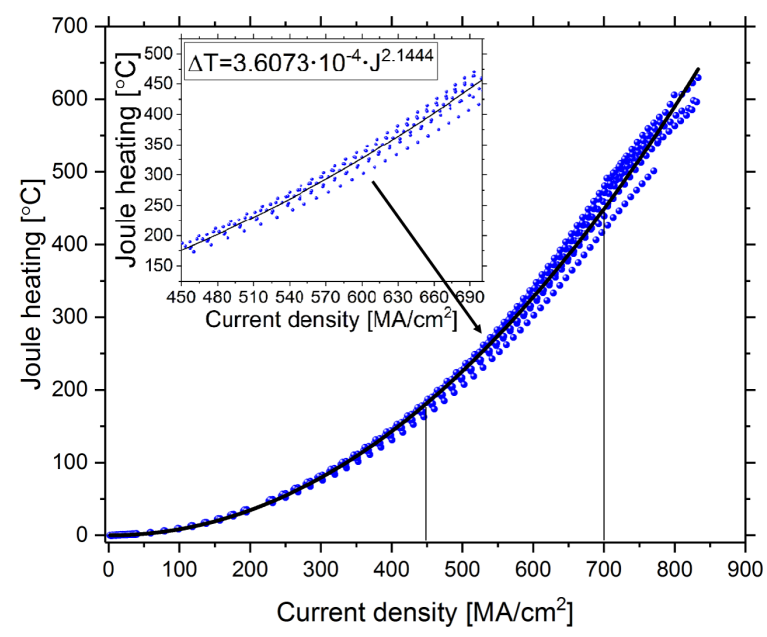

Fig. 7. JH temperature as a function of the current density in Ru_4. The data can be fit by $\Delta T=3.6073 \cdot 10^{-4} J^{2.1444}$, which allows calculating the $\mathrm{JH}$ for each current density.

(along with a polycrystalline grain structure) or the weak Co-low- $k$ interface. The differences in reported activation energies need not be surprising; it cannot be excluded that at lower temperatures, a mechanism with lower $\mathrm{E}_{\mathrm{A}}$ dominates EM failure. With the LFN measurements we only observe the lower activation energy. Conversely, standard EM tests at elevated temperatures might pick up only the higher one. Moreover, in what follows, we show that the interpretation of $\mathrm{JH}$ has an important impact on the calculation of the activation energy when using Black's law [(3)].

\section{Wafer-Level Electromigration}

Wafer-level EM was performed on samples of type $\mathrm{Ru}_{-} 4$. Fig. 6 demonstrates that these lines have a $J_{\text {Fuse }}$ of $786 \pm$ $43 \mathrm{MA} / \mathrm{cm}^{2}$. The JH for each current density can be calculated from Fig. $7\left(\Delta T=3.6073 \cdot 10^{-4} \cdot J^{2.1444}\right)$. Due to such high local temperatures, the $\mathrm{Ru}$ line undergoes an anneal during the EM test, which is confirmed by the observed decrease in line resistance during the duration of the wafer-level EM test, as shown in Fig. 8. This is attributed to recrystallization and

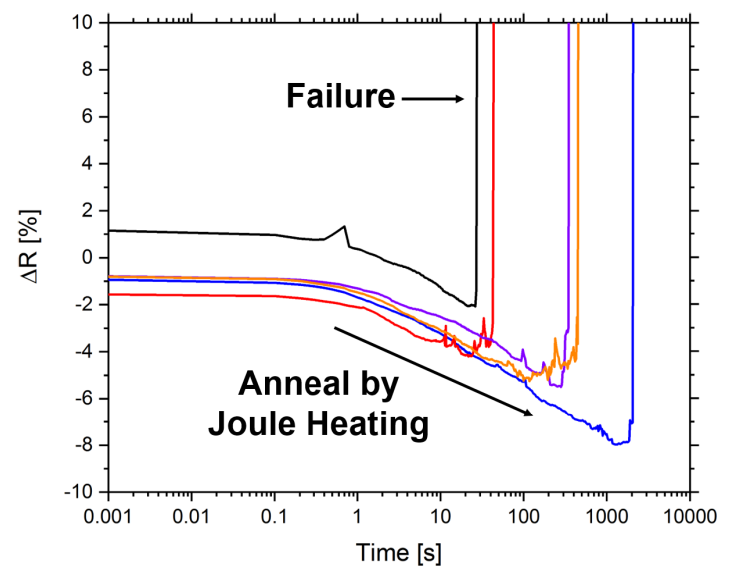

Fig. 8. Typically observed resistance evolution as a function of time in the wafer-level EM experiments on Ru_4 samples $\left(J=550 \mathrm{MA} / \mathrm{cm}^{2}\right.$, $\left.T=250{ }^{\circ} \mathrm{C}+\approx 200^{\circ} \mathrm{C} \mathrm{JH}\right)$. Initially, the resistance decreases, due to the high wire temperature, which acts like a thermal anneal.

grain growth because the $\mathrm{Ru}$ _4 samples did not undergo a forming gas anneal (FGA) after fabrication.

As mentioned earlier, obtaining EM failures in alternative metal interconnects, such as these $\mathrm{Ru}$ lines, require very high-stress conditions. Traditional EM test methods are based on accelerated testing and extract the activation energy from the Arrhenius relation of the mean time to failure, which requires at least three temperatures. A correct estimation of the temperature of the void location is thereby crucial. When testing $\mathrm{Cu}$ interconnects, JH could generally be neglected, but for alternative metals more caution is advised. Croes et al. [26] recently demonstrated that the calculation of the EM activation energy in tungsten heaters using Black's law is strongly dependent on the assumed temperature of the void. This void temperature, $T_{\text {void }}$, is the sum of the ambient temperature $T_{\mathrm{amb}}$ and the local $\mathrm{JH}$ temperature $T_{\mathrm{JH}}$. In the case of the tungsten heaters, the activation energy was found to be $0.3-\mathrm{eV}$ lower when assuming $T_{\mathrm{void}}=T_{\mathrm{amb}}$ as compared with the case where $T_{\mathrm{void}}=T_{\mathrm{amb}}+T_{\mathrm{JH}}$. The void did indeed not form in the tungsten line, but in the $\mathrm{Cu}$ injector, which is at ambient temperature. Because, also in this case, the center of the line has a much higher temperature than the contacts, it is necessary to model the temperature profile in the wire and use it to predict the actual void temperature.

\section{Calculation of the Temperature Profile in the Wire}

To estimate the temperature at the void location in the $\mathrm{Ru}$ lines, the temperature profile in the line must be calculated. The 1-D heat transport equation was solved analytically, assuming that the contacts were at ambient temperature (they act as large heat sinks). For more details, the reader is referred to [27]. The temperature profile in the wire can be described as

$$
T(x)=C_{1} \exp (\sqrt{F} x)+C_{2} \exp (-\sqrt{F} x)-G / F
$$

where

$$
F=\left(\frac{h P}{k A_{d}}\right)
$$




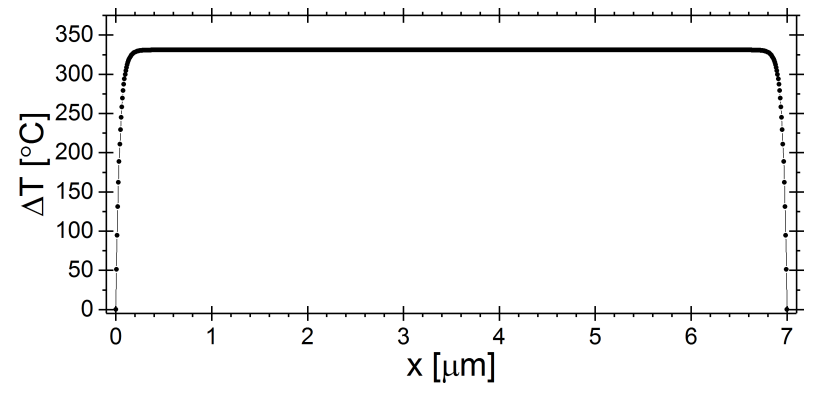

Fig. 9. Calculated temperature increase by $\mathrm{JH}$ in the $\mathrm{Ru}$ wire (length $7 \mu \mathrm{m})$ for a current density of $600 \mathrm{MA} / \mathrm{cm}^{2}$. The contacts are assumed to be at ambient temperature, the maximum temperature is reached at $200 \mathrm{~nm}$ from the contacts.

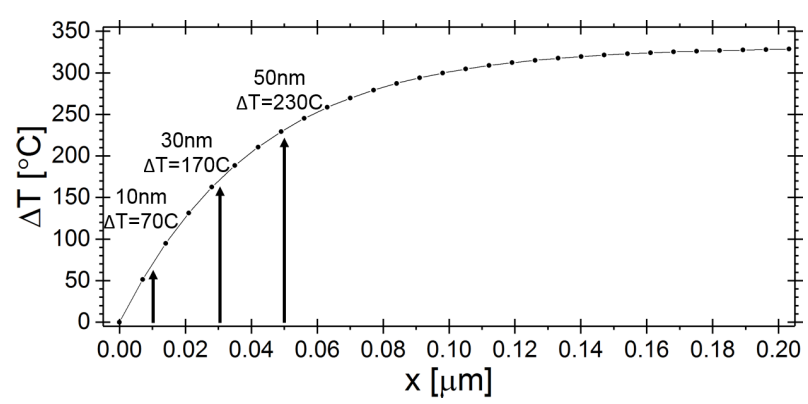

Fig. 10. Calculated temperature increase by $\mathrm{JH}$ in direct vicinity of the contact. The temperature of the void is strongly dependent on its position.

$$
\begin{aligned}
G & =-\left(\frac{h P}{k A_{d}} T_{\mathrm{amb}}+\frac{\rho}{k}\left(\frac{I}{A_{d}}\right)^{2}\right) \\
C_{1} & =T_{\mathrm{amb}}+\frac{G}{F}-C_{2} \\
C_{2} & =\frac{\left(T_{\mathrm{amb}}+\frac{G}{F}\right) \exp (\sqrt{F} L)-\frac{G}{F}-T_{\mathrm{amb}}}{\exp (\sqrt{F} L)-\exp (-\sqrt{F} L)}
\end{aligned}
$$

$h$ is the heat convection coefficient

$$
h=\frac{k_{d}}{r_{w} \ln \left(\frac{R_{d}}{r_{w}}\right)}
$$

$P$ the perimeter, $A_{d}$ the wire cross section, $\rho$ the electrical resistivity of $\mathrm{Ru}$ (measured $35.5 \mu \Omega \mathrm{cm}$ ), $I$ the applied current, and $L$ the length of the wire $(7 \mu \mathrm{m})$. The thermal conductivity of the $\mathrm{Ru}$ wire, $k$, is assumed to be $50 \mathrm{~W} / \mathrm{mK}$ (lower than the bulk value of $120 \mathrm{~W} / \mathrm{mK}$ due to thin film effects). The resulting temperature profile is shown in Fig. 9, for a current density of $600 \mathrm{MA} / \mathrm{cm}^{2}$. The average, analytical line temperature was found to correspond to the experimentally determined $\mathrm{JH}$ temperature. Fig. 10 shows the temperature profile in the direct vicinity of the contact, where voids were observed. Note that this calculation is made for a line at ambient temperature. At higher temperatures the resistance increases and even larger $\mathrm{JH}$ can occur.

A similar calculation can be made for the Co lines. Because these lines still have a significant thickness, the thermal conductivity was assumed to be $100 \mathrm{~W} / \mathrm{mK}$, and the electrical resistivity is $42 \mu \Omega \mathrm{cm}$. For a current density of $50 \mathrm{MA} / \mathrm{cm}^{2}$, an average $\mathrm{JH}$ temperature of $100{ }^{\circ} \mathrm{C}$ would be reached.

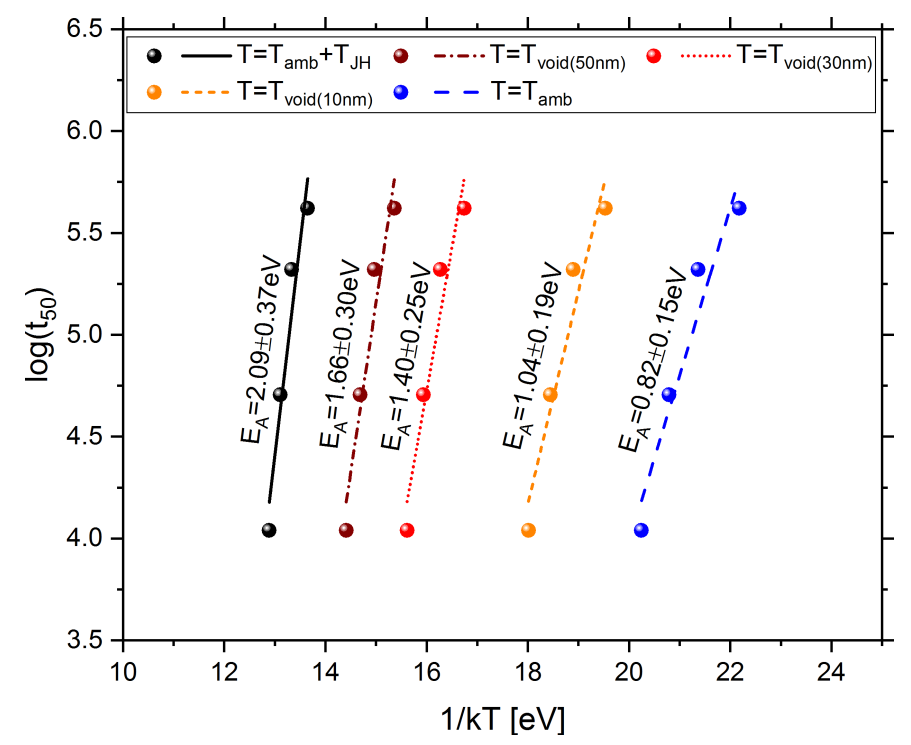

Fig. 11. Calculation of the EM activation energy using the Arrhenius relation of $t_{50}$ with temperature. The void temperature (and, thus, its location), has a large influence on $\mathrm{E}_{\mathrm{A}}$. The largest value $(2.09 \pm 0.37 \mathrm{eV})$ is found when the void is assumed to be at the $T_{\mathrm{amb}}+T_{\mathrm{JH}}$ and the lowest $(0.82 \pm 0.15 \mathrm{eV})$ if the void forms at the contact $\left(T=T_{\text {amb }}\right)$. The $E_{A}$ 's are $1.66 \pm 0.30,1.40 \pm 0.25$, and $1.04 \pm 0.19 \mathrm{eV}$ for the void at 50,30 and $10 \mathrm{~nm}$ from the contact, respectively.

In thinner lines, this temperature would further increase due to the decreasing electrical and thermal conductivity.

\section{E. Influence of Joule Heating on the EM Activation Energy}

The $t_{50}$ 's of the lognormal distributions for the lines stressed at a constant current density of $600 \mathrm{MA} / \mathrm{cm}^{2}$ and ambient temperatures $\left(T_{\mathrm{amb}}\right)$ of $250{ }^{\circ} \mathrm{C}, 275^{\circ} \mathrm{C}, 285^{\circ} \mathrm{C}$, and $300^{\circ} \mathrm{C}$ are shown in Fig. 11. The black dots indicate the total temperature calculated as $T=T_{\mathrm{amb}}+T_{\mathrm{JH}}$, where $T_{\mathrm{JH}}$ is the temperature increase due to $\mathrm{JH}$, calculated by means of Fig. 7. Using this total temperature, activation energy of $2.09 \pm 0.37 \mathrm{eV}$ could be extracted. This value is close to the value reported by $\mathrm{Hu}$ et al. [7]. Nevertheless, one should take into account that these test structures have a very large heat sink at each of the contacts. This means that one could assume that the line in the direct vicinity of the contacts is at ambient temperature (see also Fig. 10). EM-induced voids occur close to the contact such that one could assume that the void location is also at ambient temperature. The blue dots in Fig. 11 indicate the $t_{50}$ 's in this scenario, resulting in an activation energy of only $0.82 \pm 0.15 \mathrm{eV}$, which is much closer to the values observed with the LFN measurements (Ru_4 in Fig. 3). The reality, however, is likely to be somewhere in between. As discussed earlier, $\Delta T$ due to $\mathrm{JH}$ is calculated at 10,30 , and $50 \mathrm{~nm}$ from the contact (Fig. 10).

The $t_{50}$ 's, in this case, are also shown in the graph in Fig. 11, and the respective $\mathrm{E}_{\mathrm{A}}$ 's are then $1.66 \pm 0.30,1.40 \pm 0.25$, and $1.04 \pm 0.19 \mathrm{eV}$.

In addition, in Co lines, self-heating is significant [14], and therefore, the actual EM activation energy may also be lower than what has previously been reported [5], [7]. 


\section{CONCLUSION}

LFN measurements were used to calculate the activation energy of five types of Ru interconnects, fabricated with two different processing techniques (metal etch [8] and spacer defined [9]) and damascene cobalt interconnects. In all of the $\mathrm{Ru}$ samples, the activation energy was around $1 \mathrm{eV}$, albeit the different microstructures. A decrease in $\mathrm{E}_{\mathrm{A}}$ by $\sim 0.05 \mathrm{eV}$ was observed for samples without the adhesion layer.

In addition, for cobalt, the activation energy was around $1 \mathrm{eV}$.

The LFN $E_{A}$ is lower than what has previously been reported for $\mathrm{Ru}$ and $\mathrm{Co}$, and we see two possible explanations for that. First, the LFN measurements were performed near-normal operation temperatures, and therefore, limited to detecting $\mathrm{E}_{\mathrm{A}}$ 's below $1.1 \mathrm{eV}$. It is not unlikely that at higher temperatures, other mechanisms become dominant. Second, we have pointed out that standard accelerated EM tests on $\mathrm{Ru}$ interconnects result in a nonuniform temperature along with the line due to $\mathrm{JH}$. For cobalt, similar results can be expected because there, $\mathrm{JH}$ is also significant. The temperature of the void is, therefore, much lower than the average wire temperature, because the FDP is at the contact. Assuming that the void forms in close proximity of the contact (e.g., $10 \mathrm{~nm}$ ), an $\mathrm{EM} \mathrm{E}_{\mathrm{A}}$ of $\approx 1 \mathrm{eV}$ is found, which is in line with the LFN E $E_{\mathrm{A}}$.

Correct estimations of the EM activation energy by accelerated tests become increasingly challenging for $\mathrm{Ru}$ and $\mathrm{Co}$. Reliable thermal simulations will be indispensable if these tests are to be further applied to advanced interconnects consisting of alternative metals. Another solution to this problem is the application of LFN measurements, as demonstrated in this article.

\section{REFERENCES}

[1] P. Kapur, J. P. McVittie, and K. C. Saraswat, "Technology and reliability constrained future copper interconnects. I. Resistance modeling," IEEE Trans. Electron Devices, vol. 49, no. 4, pp. 590-597, Apr. 2002.

[2] A. S. Oates, "Strategies to ensure electromigration reliability of $\mathrm{Cu} / \mathrm{low}-$ k interconnects at $10 \mathrm{~nm}$," ECS J. Solid State Sci. Technol., vol. 4, no. 1, pp. N3168-N3176, 2015.

[3] B. Li, C. Christiansen, D. Badami, and C.-C. Yang, "Electromigration challenges for advanced on-chip $\mathrm{Cu}$ interconnects," Microelectron. Rel., vol. 54, no. 4, pp. 712-724, 2014.

[4] P. Kapur, G. Chandra, J. P. McVittie, and K. C. Saraswat, "Technology and reliability constrained future copper interconnects. II. Performance implications," IEEE Trans. Electron Devices, vol. 49, no. 4, pp. 598-604, Apr. 2002. [Online]. Available: http://ieeexplore.ieee.org/ document/992868/

[5] F. Griggio et al., "Reliability of dual-damascene local interconnects featuring cobalt on $10 \mathrm{~nm}$ logic technology," in Proc. IEEE Int. Rel. Phys. Symp. (IRPS), Mar. 2018, pp. 6E.3-1-6E.3-5.
[6] S. Dutta et al., "Sub-100 $\mathrm{nm}^{2}$ cobalt interconnects," IEEE Electron Device Lett., vol. 39, no. 5, pp. 731-734, May 2018.

[7] C.-K. Hu et al., "Future on-chip interconnect metallization and electromigration," in Proc. IEEE Int. Rel. Phys. Symp. (IRPS), Mar. 2018, pp. 4F.1-1-4F.1-6.

[8] S. Dutta et al., "Highly scaled ruthenium interconnects," IEEE Electron Device Lett., vol. 38, no. 7, pp. 949-951, Jul. 2017.

[9] A. Gupta et al., "High-aspect-ratio ruthenium lines for buried power rail," in Proc. IEEE Int. Interconnect Technol. Conf. (IITC), Jun. 2018, pp. 4-6.

[10] S. Dutta et al., "Thickness dependence of the resistivity of platinumgroup metal thin films," J. Appl. Phys., vol. 122, no. 2, 2017, Art. no. 025107.

[11] S. Dutta, K. Moors, M. Vandemaele, and C. Adelmann, "Finite size effects in highly scaled ruthenium interconnects," IEEE Electron Device Lett., vol. 39, no. 2, pp. 268-271, Feb. 2018.

[12] S. Beyne et al., "The first observation of p-type electromigration failure in full ruthenium interconnects," in Proc. IEEE Int. Rel. Phys. Symp. (IRPS), Mar. 2018, pp. 6D.7-1-6D.7-9.

[13] O. V. Pedreira et al., "Reliability study on cobalt and ruthenium as alternative metals for advanced interconnects," in Proc. IEEE Int. Rel. Phys. Symp. (IRPS), Apr. 2017, pp. 6B-2.1-6B-2.8.

[14] K. Croes et al., "Interconnect metals beyond copper: Reliability challenges and opportunities," in IEDM Tech. Dig., Dec. 2018, pp. 5.3.1-5.3.4.

[15] C. Adelmann et al., "Alternative metals for advanced interconnects," in Proc. IEEE Int. Interconnect Technol. Conf., May 2014, pp. 173-176.

[16] S. Beyne, K. Croes, I. De Wolf, and Z. Tókei, "1/f noise measurements for faster evaluation of electromigration in advanced microelectronics interconnections," J. Appl. Phys., vol. 119, no. 18, 2016, Art. no. 184302.

[17] S. Beyne, L. Arnoldi, I. De Wolf, Z. Tókei, and K. Croes, "Study of the enhanced electromigration performance of $\mathrm{Cu}(\mathrm{Mn})$ by low-frequency noise measurements and atom probe tomography," Appl. Phys. Lett., vol. 111, no. 8, 2017, Art. no. 083105 .

[18] S. Beyne, O. V. Pedreira, I. De Wolf, Z. Tókei, and K. Croes, "A novel electromigration characterization method based on low-frequency noise measurements," Semicond. Sci. Technol., vol. 34, no. 7, Jun. 2019, Art. no. 075002.

[19] S. Beyne, O. V. Pedreira, H. Oprins, I. De Wolf, Tókei, and K. Croes, "Electromigration activation energies in ruthenium interconnects," in Proc. IEEE Int. Interconnect Technol. Conf. (IITC), Jun. 2019.

[20] M. H. van der Veen et al., "Damascene benchmark of Ru, Co and $\mathrm{Cu}$ in scaled dimensions," in Proc. IEEE Int. Interconnect Technol. Conf. (IITC), Jun. 2018, pp. 172-174.

[21] P. Dutta, P. Dimon, and P. M. Horn, "Energy scales for noise processes in metals," Phys. Rev. Lett., vol. 43, no. 9, pp. 646-649, Aug. 1979.

[22] P. Dutta and P. M. Horn, "Low-frequency fluctuations in solids: $\frac{1}{f}$ noise," Rev. Modern Phys., vol. 53, no. 3, pp. 497-516, 1981.

[23] J. R. Black, "Electromigration-A brief survey and some recent results," IEEE Trans. Electron Devices, vol. ED-16, no. 4, pp. 338-347, Apr. 1969.

[24] A. B. Anderson and M. K. Awad, "Binding of $\mathrm{Ru}, \mathrm{O}$, and $\mathrm{RuO}_{n}(\mathrm{n}=1-4)$ to the $\mathrm{Ru}$ (001) surface: Structures, stabilities, and diffusion barriers," Surf. Sci., vol. 183, nos. 1-2, pp. 289-301, 1987.

[25] M. Y. Chou and J. R. Chelikowsky, "Structural properties of the Ru (0001) surface," Phys. Rev. B, Condens. Matter, vol. 35, no. 5, pp. 2124 2127, 1987.

[26] K. Croes et al., "Understanding EM-degradation mechanisms in metal heaters used for Si photonics applications," in Proc. IEEE Int. Rel. Phys. Symp. (IRPS), Mar. 2019, pp. 1-4.

[27] L.-C. Chen, H. Oprins, B. Vandevelde, G. Brizar, D. Vanderstraeten, and E. Blansaer, "Electro-thermal-mechanical analysis of a HQUAD package for high current and high power application," in Proc. THERMINIC, Sep. 2005, pp. 173-178. 